\title{
- Contextualização dos impactos ambientais em áreas de extração de gemas no Povoado de Taquaral, Itinga (MG)
}

Ana Paula Rufino Santos ${ }^{1}$

Jenny Silva Pêgo²

Emerson de Oliveira Muniz ${ }^{3}$

\section{Resumo}

O presente estudo teve como recorte espacial de análise as áreas de extração de gemas do Povoado de Taquaral, no município de Itinga, pertencente ao distrito mineralógico de Araçuaí (MG). Foram visitados oito garimpos: Lagoa da Malva, Bode, Lajedo, Manguinha, De Zá, Faixa, Piauí e Jurema. Partindo de revisões bibliográficas, cujo enquadramento temático deu-se no universo dos riscos ambientais, este trabalho apresentou um debate entre dois contextos típicos e dilemáticos dessas áreas de exploração. 0 primeiro contexto (socioeconômico) diz respeito à importância histórica da atividade garimpeira de gemas no Vale do Jequitinhonha como geradora de trabalho e renda para muitos indivíduos que habitam a região. $O$ segundo contexto diz respeito à geração de um conjunto de degradações socioambientais que se intensificam com a continuidade da exploração nas áreas de lavra. A partir desse pressuposto, o objetivo baseou-se no diagnóstico e na interpretação das relações socioambientais próprias dos ambientes de garimpo e na existência de riscos advindos da atividade no Povoado de Taquaral, Itinga (MG), com ênfase na degradação dos recursos naturais. Tratou-se de uma pesquisa de caráter qualitativo. A abordagem desenvolveu-se mediante um estudo de caso obedecendo a três etapas sequenciais: exploratória, coleta de dados e estudos de campo balizada em métodos ad hoc. 0 trabalho constatou a existência de diversas tipologias de riscos, além da condição de vulnerabilidade ecossistêmica local pela exploração mineral sem qualquer tipo de medida de compensação.

Palavras-chave: Garimpo de gemas. Compensação ambiental. Danos ambientais.

\section{Introdução}

Dentro do longevo processo de exploração dos recursos minerais no Brasil, a busca por gemas preciosas ajudou na interiorização da ocupação colonial, sendo inclusive um dos motes originais da ocupação (CORNEJO; BARTORELLI, 2010). A Companhia de Pesquisa de Recursos Minerais (CPRM, 2003) classifica o Vale do Jequitinhonha como uma das mais relevantes áreas produtoras de gemas do mundo, o que justifica a afirmação de Vieira (2012) de que a existência dos garimpos nessa região tem caráter histórico. 0 autor destaca a importância delas para a criação e povoamento de diversas cidades, como Berilo, Diamantina, Pedra Azul, Rubelita, entre outras. Foi o que se deu no

1 Instituto Federal de Educação, Ciência e Tecnologia do Norte de Minas Gerais - IFNMG. Teófilo Otoni, Minas Gerais, Brasil. anapaularufinosantos@gmail.com. Rua Inhá Maria, n 144, Teófilo Otoni (MG). CEP 39802-028.

2 Instituto Federal de Educação, Ciência e Tecnologia do Norte de Minas Gerais - IFNMG. Teófilo Otoni, Minas Gerais, Brasil. jenny.spego@hotmail.com. Rua Inhá Maria, n 144, Teófilo Otoni (MG). CEP 39802-028.

3 Instituto Federal de Educação, Ciência e Tecnologia do Norte de Minas Gerais- IFNMG. Araçuaí, Minas Gerais, Brasil. muni.2002@uol.com.br. BR 367, km 278, s/n - Zona Rural, Araçuaí (MG). CEP 39600-000 
Povoado de Taquaral, situado em um núcleo de povoamento surgido às margens do Rio Jequitinhonha em função da descoberta e extração de gemas.

0 primeiro contexto abordado neste estudo diz respeito à importância histórica da atividade garimpeira de gemas como geradora de trabalho e renda para muitos indivíduos que habitam a região. Quer seja como atividade principal e permanente, quer seja como esporádica ou sazonal para o complemento da renda familiar, fato é que os garimpos regionais continuam a empregar trabalhadores com os mais variados matizes: jovens, idosos, residentes urbanos ou rurais, locais ou forasteiros e com níveis de escolaridade e de domínio do ofício diferenciados. Há na região todo um contexto sociolaboral propiciado pela extração e comercialização das riquezas gemológicas ali existentes. É o contexto socioeconômico criado pela mineração de gemas nos garimpos do Vale de Jequitinhonha.

Os garimpos apresentam, dessa forma, relevância social, uma vez que contribuíram (e contribuem) para o processo de desenvolvimento de várias povoações, pois em muitos dos casos, a economia desses núcleos baseia-se no recurso levantado pela atividade. No caso específico de Taquaral, ao perpassar gerações, o garimpo não é apenas uma fonte de subsistência local, mas é também caracterizador da formação histórica, social e cultural de um povoado inserido no Médio Jequitinhonha, uma região fustigada pelos efeitos deletérios das pequenas taxas de pluviosidade anual. As riquezas escondidas no subsolo local alimentam a utopia de jovens e adultos a continuar residindo ali e persistindo no trabalho braçal diário, movidos pela esperança de mudanças do cenário de carência ou penúria, buscando por melhores condições de vida e reconhecimento do ofício como agente de transformação.

O segundo contexto que se estabelece em áreas garimpeiras é uma consequência do primeiro e diz respeito à geração de um conjunto de degradações socioambientais que se intensificam com a continuidade da exploração nas áreas de lavra. Essas degradações exemplificam-se nos impactos sobre o ecossistema local e o entorno dos garimpos, assim como na situação de trabalho dos garimpeiros, expostos a toda sorte de condições insalubres que acabam por combalir seus organismos e predispor o aparecimento de doenças, com consequente perda de capacidade laboral e efeitos negativos no cotidiano social desses trabalhadores e seus dependentes.

Se por um lado as atividades garimpeiras de gemas oferecem benefícios econômicos, por outro, em função das técnicas de extração ineficientes e degradadoras utilizadas, produzem muitos impactos ambientais e sociais negativos, que colocam em risco a saúde dos próprios garimpeiros, a qualidade de vida da comunidade ao redor e a integridade do meio ambiente local (MILANEZ; PUPPIM, 2009).

Assim, nas localidades onde ocorre a extração de gemas, uma série de relações socioambientais acaba por se estruturar, como as muitas ameaças e vulnerabilidades existentes nas áreas de lavra, que fazem delas um espaço em que diferentes tipos de riscos são produzidos e amplificados. Nesse sentido, o presente trabalho teve como objetivo o diagnóstico e a interpretação de algumas das relações socioambientais e desgastes próprios dos ambientes do garimpo de gemas no Povoado de Taquaral, Itinga (MG), com ênfase na degradação dos recursos naturais.

\section{Material e métodos}

A metodologia adotada no presente trabalho caracterizou-se como uma pesquisa de campo de caráter qualitativo, com base na coleta de dados oriundos de visitas "in loco", aplicação de questionários e realização de entrevistas. A pesquisa é classificada como qualitativa por seu caráter exploratório, objetivando traduzir e expressar o sentido dos diversos fenômenos do mundo social, o que reduz a distância entre o indicador e indicado, teoria e dados, contexto e ação (MAANEN, 1979). 
Em função da inexistência de estudos mais acurados quanto à avaliação dos impactos ambientais gerados pelos garimpos de gemas em lavras das imediações do Povoado de Taquaral, métodos "ad hoc" foram adotados como uma linha-mestre na pesquisa. Bastos e Almeida (2009) defendem que essas metodologias auxiliam na avaliação dos impactos ambientais de forma simples e objetiva, sendo adequadas para casos de escassez de dados.

Os mesmos autores ponderam ainda sobre a vantagem de uma estimativa rápida de avaliação de impactos de forma organizada e compreensível; no entanto, como desvantagem tem-se a possibilidade de não oferecer um exame detalhado das intervenções e variáveis ambientais ao se adotar esses procedimentos metodológicos.

A princípio, a abordagem desenvolveu-se mediante um estudo de caso, com recorte espacial definido e que ,com base em André (2005), respeitou três fases principais, a exploratória, coleta de dados e análise sistemática dos dados. Assim, para alcançar os objetivos propostos pelo trabalho, a metodologia a ser adotada seguiu as etapas elencadas a seguir.

A primeira fase da pesquisa baseou-se em uma revisão bibliográfica feita entre os meses de fevereiro e setembro de 2014 acerca das concepções teóricas quanto ao universo dos riscos na atividade mineradora de pequena escala, bem como do levantamento de trabalhos acadêmicos já publicados e relacionados aos impactos ambientais encontrados em áreas de garimpagem. Além de permitir a fundamentação conceitual do projeto de pesquisa proposto, tal procedimento também contribuiu para o entendimento de abordagens metodológicas já empregadas em casos similares ao objeto de estudo definido. Ainda nessa fase foram consultadas as principais legislações que buscam normatizar o trabalho minerador em garimpos nas esferas federal, estadual e municipal.

A segunda etapa, mais pragmática, envolveu a coleta de dados e foi realizada nos meses de fevereiro, outubro, novembro e dezembro de 2014. Foram pesquisados registros demográficos sobre Taquaral e, de maneira paralela, realizadas visitas na área em estudo e que atenderam a diferentes interesses. Realizaram-se observação e registro fotográfico das características geobiofísicas da área (clima, geologia, solo, geomorfologia, vegetação e hidrografia), interpretação "in loco" das condições de trabalho dos garimpeiros nas áreas de lavra e, com uso de um aparelho receptor manual do sistema GPS $^{5}$, definiram-se as coordenadas geográficas das lavras visitadas. Posteriormente foi feita a implantação das coordenadas das lavras em uma base cartográfica da área disponível no software GPS TrackMaker.

As visitas ocorreram em três momentos distintos: a primeira realizou-se no dia 21 de fevereiro de 2014, no garimpo Lajedo. A segunda visita ocorreu no dia 03 de outubro de 2014 nos garimpos Lagoa da Malva, Manguinha, Bode, Lavra De Zá e Jurema. A terceira e última deu-se no dia 12 de dezembro de 2014, na Lavra do Piauí, Lajedo (pela $2^{a}$ vez) e Faixa. Todas as visitas às lavras foram com o objetivo inicial do conhecimento de como se dá o processo de extração de gemas na região e das condições de risco e desgastes ambientais encontradas nelas.

Com específico foco nas condições de trabalho existentes nas áreas definidas, foram realizadas entrevistas semiestruturadas com dois garimpeiros experientes do Povoado e que ainda trabalham na atividade de extração de gemas. As entrevistas foram destinadas à obtenção de respostas livres, possibilitando obter informações mais ricas e variadas a respeito dos objetivos de investigação do estudo em questão. A aplicação de questionários por sua vez deu-se a indivíduos de ambos os sexos e diferentes faixas etárias que atuam ou já atuaram na atividade garimpeira. O objetivo dessa aplicação

4 Métodos "ad hoc" são aqueles baseados no conhecimento empírico de especialistas no assunto e/ou da área em questão" (BASTOS e ALMEIDA, 2009, p. 89).

5 GPS: Global Position System. Em português, Sistema de Posicionamento Global. 
consistiu em obter informações relacionadas aos mecanismos de extração de gemas e dos níveis de percepção e aceitabilidade dos riscos ambientais por parte dos garimpeiros.

A fase da análise sistemática dos dados obtidos em campo permitiu, ainda que panoramicamente, um melhor entendimento dos problemas ambientais existentes nos garimpos visitados e das situações de risco observadas nas áreas de extração de gemas do povoado de Taquaral.

\section{Resultados e discussão}

\section{Processo de Extração de Gemas e Riscos Associados}

O Povoado de Taquaral está localizado no município de Itinga, a sudoeste do distrito-sede, na mesorregião do Jequitinhonha, no nordeste de Minas Gerais. Encontra-se na margem direita do Rio Jequitinhonha, com população absoluta estimada em 2.364 habitantes, conforme consta no Mapa Epidemiológico de 2014 consultado na sede do Programa de Saúde da Família (PSF) de Taquaral.

$\mathrm{Na}$ oportunidade do primeiro levantamento bibliográfico, constatou-se a escassa existência de trabalhos que associam garimpos de gemas e degradação socioambiental, ao contrário do que ocorre quando a ênfase é apenas geológica, interessada no potencial produtivo em rochas pegmatíticas, com inúmeras publicações existentes. Os trabalhos mais alinhados com a pesquisa, portanto, são: Marques (2011), um pioneiro estudo, ainda que genérico, sobre a degradação ambiental provocada pelos garimpos no Povoado de Taquaral; Nascimento (2009), dissertação que analisou conjuntamente impactos socioambientais e consequências na saúde do trabalhador em garimpos de esmeraldas no município de Campo Verde (GO); Pedrosa-Soares e Dias (2005), publicação que apresentou informações acerca da variedade gemológica e do processo de formação geológica do Vale do Jequitinhonha; Dias (2012), que se tratava da caracterização geoquímica das rochas encontradas no Complexo Jequitinhonha.

Grande parte da produção mundial de pedras coradas é de responsabilidade do Estado de Minas Gerais, que conta com aproximadamente $30 \%$ de toda produção comercializada (TEIXEIRA; OLIVEIRA, 2005). Assim, com um subsolo riquíssimo, o Vale do Jequitinhonha é reconhecido mundialmente por produzir uma infinidade de gemas, com importantes ocorrências de turmalina nas diversas variedades, indicolita (todos os matizes de azul, muito valorizada no mercado e de rápida comercialização), verdelita (matizes de verde), rubelita (rosa e/ou vermelha), schorlita (preta), acroíta (incolor), além das elbaítas com bicoloração, como a melancia (verde e vermelha). Também são encontradas na área variedades gemológicas do mineral berilo, como a água-marinha (azul), a morganita (rosa), o heliodoro (amarelo dourado), o estanho (cassiterita), feldspato, lítio (ambligonita, espodumênio e petalita), mica, nióbio-tântalo (columbita-tantalita) e quartzo, distribuídos nos municípios de Virgem da Lapa, Rubelita, Coronel Murta, Itinga, Medina e Pedra Azul (CPRM, 2003).

Em função da ocorrência relativamente comum de minerais corados nas imediações do Povoado, o exercício da atividade de garimpagem de gemas constitui-se em um traço cultural local transmitido e perpassado de geração em geração. A maioria dos garimpeiros desloca-se a pé até o local de trabalho, sendo que alguns dispõem de motocicleta ou bicicleta. Esse fácil acesso é explicado pela inúmera quantidade de lavras próximas às residências ou nas imediações de Taquaral (Bode, Lajedo, Jurema e De Zá). Em lavras situadas em distância mais expressiva (Malva, Manguinha, Faixa e Piauí), o transporte é feito por veículos, motocicletas ou mesmo a cavalo em alguns casos.

No processo de extração de gemas, os garimpeiros submetem-se a diversas situações de risco acidentes pelo uso de explosivos, queda de barreiras, explosões e a própria exposição a doenças ocupa- 
cionais (silicose), presentes nas diferentes etapas laborais. Desde as primeiras escavações para abertura da mina ou de túneis, passando pelo desmonte da rocha com ou sem o uso de explosivos, na retirada do material desmontado do ambiente subterrâneo e até no próprio caminhar constante na área do garimpo, em todas essas funções, os garimpeiros atuam com mínimas condições de segurança.

Geralmente a exploração ocorre de forma manual e rudimentar, mas existem poucos garimpos que utilizam recursos mecanizados e outros instrumentos de cunho tecnológico para facilitar a retirada das gemas. Rodrigues (2012) discute que, devido à simplicidade do trabalho em relação às técnicas e conhecimentos necessários para a realização da extração de minérios e pedras preciosas, a atividade na maioria das vezes é feita de forma rudimentar. Tal realidade foi claramente constatada nos garimpos visitados. Conforme Marques (2011), o processo de retirada das pedras preciosas do subsolo de Taquaral e imediações ocorre mediante uma sequência de etapas: escolha do local da catra, fichamento do cascalho, desenvolvimento da catra, furação da mina, preparação do fogo, explosão, tempo de espera para explosão, retorno ao serviço, retirada das pedras preciosas, lavagem e classificação, pesagem, agregação de valor e comercialização.

A escolha do local a ser lavrado depende muito do conhecimento prático, da experiência dos garimpeiros e de uma diversidade de fatores relacionados às características físicas da área, entre elas os tipos de solo, a feição topográfica, as condições de escoamento e infiltração da água e, sobretudo, a situação litológica local, ou seja, a definição de uma rota de escavação que, na visão garimpeira, facilite e potencialize as chances do encontro dos minerais almejados.

Definido isso, ocorre a perfuração e abertura dos túneis ou minas, popularmente conhecidas como catras. Tal método exige a abertura de galerias subterrâneas em locais com tipos pedológicos e litológicos diversificados. Devido ao conhecimento empírico que possuem, os garimpeiros desmontam os corpos de pegmatito ou os granitos hospedeiros desse, guiando-se por características nas rochas que em geral indicam a localização mais propícia da existência de minerais preciosos. As chamadas catras são construídas verticalmente no formato retangular ou quadrado e dão acesso aos túneis que podem seguir horizontalmente em linha reta ou, quando necessário, em outras direções em níveis cuja profundidade é maior. Os garimpos do Povoado de Taquaral diversificam-se quanto à profundidade, podendo variar entre 5 e 150 metros.

Em função do alto custo e das dificuldades de aquisição por parte dos garimpeiros, o uso de explosivos (chamado de fogo pelos trabalhadores) na mina ocorre quando as rochas tornam-se muito resistentes à escavação rudimentar e quando há indícios de sucesso na exploração.

A preparação do explosivo exige um cuidado especial, sendo um momento decisivo, uma vez que qualquer descuido pode afetar diretamente a qualidade do mineral a ser extraído, além do iminente risco de acidentes, como desmoronamentos ou soterramentos.

A faixa de tempo para retorno pode variar entre quinze e vinte minutos ou de uma a duas horas dependendo do local lavrado e do número de detonações realizadas. O garimpeiro normalmente só entra no túnel no momento em que a poeira está parcial ou totalmente dissipada.

Retirado o bem precioso, todo material é lavado, classificado, pesado e valorado. 0 comércio pode ser feito nas próprias imediações do próprio Povoado, por meio dos chamados "pedristas", que compram as gemas e peças de coleção dos garimpeiros e as revendem em outros centros do Brasil e do exterior. 


\section{Análise dos efeitos ambientais no meio físico, biótico e antrópico}

As ações humanas alteram o meio ambiente, sendo a mineração uma atividade básica da economia mundial. Por meio dela, a humanidade extrai recursos minerais que possibilitam abastecer inúmeras cadeias produtivas. Assim, se por um lado ela é essencial na dinamização da economia e no bem-estar da sociedade, por outro a atividade mineradora em grande ou pequena escala gera passivos ambientais importantes.

A mineração é responsável por provocar uma série de efeitos não desejados, as chamadas "externalidades", que podem ser descritas por alterações ambientais, conflitos de uso do solo, depreciação de imóveis circunvizinhos e geração de áreas degradadas. (BITAR, 1997). As "externalidades" de cunho ambiental podem ser observadas nas imediações de garimpos de gemas. São muitos os impactos ambientais decorrentes dessa atividade, o Instituto de Pesquisas Tecnológicas (1992) exemplifica impactos como "desmatamentos, queimadas, alteração nos aspectos qualitativos e no regime hidrológico dos cursos de água; fuga de animais silvestres; desencadeamento dos processos erosivos e turbidez das águas", entre outros. De todo modo, o dano ambiental ocasionado pela extração de gemas no Povoado de Taquaral afeta diversificadamente os meios físico, biótico e antrópico da referida localidade. Isso foi comprovado na série de visitas realizadas no período de fevereiro de 2014 a dezembro de 2014 em oito garimpos do Povoado.

Tais visitas possibilitaram observações acerca dos impactos ocasionados pela atividade, pois é evidente que a garimpagem gera processos de erosão do solo que, ao se intensificarem, contribuem para a sua completa desestruturação, tornando ineficiente o mecanismo de retenção e reciclagem de nutrientes nas áreas afetadas pela atividade de extração. Esse aspecto, somado à semiaridez do contexto regional, dificulta bastante o aproveitamento dos solos afetados pelos garimpos para finalidades de cultivo e pastoreio.

A deflagração e a manutenção dos processos erosivos no solo redundam em expressiva degradação do ambiente. A erosão do solo é potencializada neste caso pela abertura de túneis ou minas que facilitam a ação erosiva da água, que acelera a formação de crateras, sulcos, ravinas e voçorocas. Tais efeitos erosivos são facilmente visualizados nos garimpos do Bode, De Zá, Piauí, Lajedo e Faixa.

Constatou-se ao longo do trabalho que a garimpagem provoca impactos ambientais diversificados em função de seu caráter dilapidador. Observou-se o desencadeamento de processos erosivos e o empilhamento indevido do rejeito mineral, favorecendo substancialmente a descaracterização da paisagem local. Além disso, as pilhas de rejeito também podem influenciar os mecanismos de drenagem superficial alterando seu escoamento natural.

Evidenciou-se também nas áreas visitadas, sobretudo nas lavras do Piauí, Lajedo e Bode, a alteração das feições topográficas originadas pela abertura de cavas de maior amplitude, a aparição induzida de áreas de maior declividade, a construção de aterros e o entulhamento de talvegues com material mineral descartado. Ainda que não aferido neste estudo, o descarte desordenado e aleatório desse material mineral pode, além de contaminar o solo, inviabilizá-lo completamente para a prática agropastoril pelo espalhar significativo de sedimentos de menor ou maior granulometria.

Observa-se um acúmulo representativo de rejeito estéril nos garimpos Lajedo, Bode, Piauí e Lagoa da Malva, que apesar de ser um material comercializável, em geral, não é aproveitado pelos garimpeiros, o que configura uma situação de desperdício de minerais industriais (TAVARES et al., 2007). Como o foco dos garimpeiros está somente na procura das gemas e das peças de coleção, pilhas de material minerado contendo feldspato, micas, quartzo, albita são deixadas ao léu sem qualquer uso ou medida de controle. 
A abertura de vias de acesso para o tráfego de equipamentos ou transporte é responsável por acelerar de forma significativa a derrubada da vegetação nativa, além disso, a retirada de madeira pode ser usada para construções de apoio, fogões à lenha ou estruturas específicas nos próprios garimpos. Verifica-se nos garimpos Lavra De Zá, Lagoa da Malva e Bode a presença de queimadas e supressão de vegetação em diversos pontos dos locais analisados.

A ocupação de áreas próximas a córregos, topos de morro e nascentes contribui para um conjunto de desgastes ecossistêmicos do Povoado. Como exemplo, podemos citar o garimpo do Piauí que se situa em um topo de morro com certa proximidade do Córrego Piauí e onde ocorreu a remoção da vegetação para abertura da cava que dá acesso à lavra subterrânea.

O desmonte do material consolidado (rocha) em alguns garimpos como Lajedo, Bode e Piauí ocorre mediante uso de explosivos, fato esse prejudicial à população residente no entorno e à fauna local. Existem algumas minas abandonadas que permitem o surgimento de um alto grau de risco tanto para a população residente, como para animais domésticos (bois, cavalos e cães), que circulam pelo local. Na estação chuvosa, os túneis podem se constituir em locais de proliferação de doenças pelo acúmulo de água parada ou provocar acidentes diversos.

O abandono da lavra pode ocorrer por queda na produtividade na mina ou por falta de recursos financeiros para manter a continuidade da exploração. Alguns garimpeiros fecham a entrada da cava com a instalação de grades e cadeados para impedir que outros venham a explorar o mesmo serviço.

\section{Considerações Finais}

O processo de ocupação de Taquaral deu-se em função do garimpo, que foi fundamental para a formação dos contextos socioeconômico e socioambiental, cultural e histórico, o que evidencia a relevância da atividade para a subsistência e o desenvolvimento local.

Ao avaliar a condição do ambiente natural, a pesquisa realizada no Povoado de Taquaral permitiu o conhecimento de uma realidade ambiental comprometida e vulnerável. O exercício da atividade sem qualquer mecanismo de controle ou mitigação contribui para a existência de riscos e passivos ambientais extensos e duradouros. Tais problemas iniciam-se no processo de exploração pela perda do solo e consequente erosão, descaracterização da paisagem original pelo empilhamento de rejeitos, remoção da vegetação pela abertura de estradas que dão acesso às áreas de exploração, ocupação de áreas próximas a córregos, nascentes e o próprio abandono das lavras, que pode ocasionar acidentes a animais, aos próprios garimpeiros ou constituir-se em focos de proliferação de doenças. Todos esses fatores citados contribuem para a caracterização da atividade garimpeira como um ambiente de risco e vulnerabilidade ambiental.

\section{Contextualization of environmental impacts in extraction areas of Taquaral village gems, Itinga (MG)}

\section{Abstract}

The present study analyzed gem extraction areas in the village of Taquaral, in Itinga city, which is located in the mineralogical district of Araçuaí (MG). In the research, eight mines were visited: Lagoa da Malva, Bode, Lajedo, Manguinha, De Za, Faixa, Piaui and Jurema. Starting from bibliographic reviews, whose thematic framework took place in the universe of environmental risks, this 
study presented a debate between two typical and problematic contexts of these exploration areas. The first context (socio-economic) concerns the historical importance of mining gems activity in Jequitinhonha Valley, as a job generator and income for many people living in the region. The second context concerns the generation of a set of environmental degradation which intensify with continued operation in the mining areas. Based on this assumption, the objective was built on the diagnosis and interpretation of their own socio-environmental relations of prospecting environments and the existence of risks arising from the activity in the village of Taquaral, Itinga (MG), with emphasis on natural resource degradation. A qualitative research was carried out. The approach was developed through a case study obeying three sequential steps: the exploratory, the data collection phase and field studies supported by ad hoc methods. The study found out that there were various types of risks, besides the local ecosystem vulnerability condition for mineral exploration without any compensatory measure.

Keywords: Gem mines. Environmental compensation. Environmental damage.

\section{Referências}

ANDRÉ, M. E. D. A. de. Estudo de caso em pesquisa e avaliação educacional. Brasília: Liberlivros, 2005. p. 7-70.

BITAR, O. Y. Avaliação da recuperação de áreas degradadas para a mineração, Região Metropolitana de São Paulo. SP, 1997.

BASTOS, A. C. S.; ALMEIDA, J. R. de. Licenciamento ambiental brasileiro no contexto da avaliação de impactos ambientais. In: CUNHA, S. B. da; GUERRA, A. J. T. (orgs). Avaliação e perícia ambiental. São Paulo: Bertrand Brasil, 2009, p. 77-113.

CORNEJO, C.; BARTORELLI, A. Minerais e pedras preciosas do Brasil. São Paulo: Solaris Edições Culturais, 2010.

COMPANHIA DE PESQUISA DE RECURSOS MINERAIS - CPRM. Mapa Geológico de Minas Gerais. Belo Horizonte: CPRM/COMIG, 2003. Escala 1:1.000.000. (Meio Digital).

DIAS, T. G. Caracterização Geoquímica e Geocronológica do Complexo Jequitinhonha na área-tipo, Orógeno Araçuaí. Belo Horizonte. UFMG. 2012.

INSTITUTO DE PESQUISAS TECNÓLOGAS - IPT. Curso de Geologia de Engenharia aplicada a problemas ambientais. São Paulo, 1992, v. 3. 291 p.

MAANEN, J. V. Reclaiming qualitative methods for organizational research: a preface, Administrative Science Quarterly, v. 24, n. 4, Dec. 1979, p. 520-526.

MARQUES, M. P. A degradação Ambiental provocada pelo Garimpo no Povoado de Taquaral - Itinga (MG). Curso de aperfeiçoamento em Educação Ambiental. UFMG. Araçuaí. 2011.

MILANEZ, B.; PUPPIM, J. A. Ambiente, pessoas e labor: APLs além do desenvolvimento econômico na mineração de opalas em Pedro II, no Piauí. Cadernos Ebape. BR, v. 7, n. 4, artigo 1, Rio de Janeiro, dez. 2009, p. 528-546. 
NASCIMENTO, I. B. Problemáticas socioambientais e implicações à saúde do trabalhador: o caso do garimpo de esmeraldas em Campos Verdes - GO. 2009. 152 f. Dissertação (Mestrado em Geografia) Instituto de Ciências Humanas, Universidade de Brasília, Brasília, 2009.

PEDROSA-SOARES, A. C.; DIAS, P. H. A. Geologia e Recursos Minerais do Município de Araçuaí, Minas Gerais. In: MELO, M. C. (Org.). Cartografia Temática, Belo Horizonte, Centro Tecnológico de Minas Gerais - CETEC, 2005, v. 1, p. 8-32.

RODRIGUES, C. C. GARIMPO: Extrativismo e precariedade das relações sociais de produção no Seridó paraibano. In: XII Jornada do Trabalho, Presidente Prudente, SP, Anais...Presidente Prudente: UFPB, 2012.

TAVARES, S. T. P.; CASTAÑEDA, C.; SOARES, A. C. P. Análise sistêmica da exploração mineral e o seu contexto sócio-econômico no Médio Jequitinhonha, MG. Geonomos. v. 15, n. 2, p. 59-63, 2007.

TEIXEIRA, M. B. S., OLIVEIRA, P. M. Aplicação do metaprojeto no desenvolvimento de anéis com a utilização de gemas de baixo valor intrínseco. [S.I.:s.n.], 2005.

VIEIRA, V. C. A condição social e econômica do garimpeiro da cidade de Diamantina: Uma história contada por seus protagonistas. UFVJM, Minas Gerais - Brasil. Revista Vozes dos Vales. n. 2 Ano I - 10/2012.

\section{Histórico editorial}

Submetido em: 03/09/2015

Aceito em: 16/12/2015 